\title{
Sağlık Hizmetleri Meslek Yüksek Okulu Anestezi Bölümü Öğrencilerinin Öğrenme Stratejileri
}

\author{
Learning Strategies of Students in the Vocational School
}

Fidan KÜDÜR ÇIRPAN, Asu GÜRER, Albena GAYEF, Emel KAPLAN

\begin{abstract}
ÖZ
Öğrenme, bireyin aktif ve bilinçli olarak bazı stratejileri kullanarak çevreden bilgi edinme, hafizada var olan bilgilerle birleştirerek kalıcı davranışlar oluşturma süreci olarak tanımlanmaktadır. $\mathrm{Bu}$ araştırma, Anestezi eğitimi alan öğrencilerin öğrenme stratejilerinin belirlenmesi ve bunlarla ilişkili olabilecek özellikleri incelemek amacıyla kesitsel tipte tanımlayıcı bir çalışma olarak planlandı. Araştırma kapsamında 142 öğrenciye ulaşılmıştır. Araştırmada, veri toplama amacıyla "Öğrenme Stratejileri Ölçeği" kullanılmıştır. Verilerin değerlendirilmesinde SPSS 17.0 istatistik programı kullanılmıştır. Veriler sıklık dağılımları, tek yönlü varyans analizi (ANOVA), t-testi ile değerlendirilmiştir. Anestezi Bölümü öğrencilerinin dikkat stratejileri puan ortalaması 15,26 $\pm 2,33$; tekrar stratejileri puan ortalamas1 $16,10 \pm 2,46$; anlamlandırma stratejileri puan ortalaması $24,41 \pm 4,95$; belleğe yerleştirme stratejileri puan ortalaması $6,69 \pm 1,59$; hatırlama stratejileri puan ortalamas1 $13,64 \pm 2,93$; bilişi yönetme stratejileri puan ortalaması 17,26+3,66; duyuşsal stratejiler puan ortalaması 20,45 $\pm 3,71$ olarak saptanmıştır. Araştırma sonucunda, Anestezi Bölümü öğrencilerinin öğrenme stratejileri için en fazla anlamlandırma, tekrar ve duyuşsal stratejileri kullanmakta olduğu saptandi. Tekrar stratejileri puan ortalaması açısından 1.sınıf 1.öğretim ve 2.sınıf 2.ögretim arasında istatistiksel olarak anlamlı farklılık saptanmıştır $(\mathrm{p}<0.05)$. Sonuç olarak, öğrencilerin kendi öğrenme stratejilerini saptamaları ve geliştirmeleri gerektiği önerilmiştir.
\end{abstract}

Anahtar kelimeler: Anestezi Teknikeri, Öğrenme, Öğrenme Stratejisi

Fidan KÜDÜR ÇIRPAN (四), Asu GÜRER

Marmara Üniversitesi Sağllk Hizmetleri Meslek Yüksekokulu Anestezi Programı

e-mail: fidan.kudur@marmara.edu.tr

Albena GAYEF

İstanbul Bilim Üniversitesi Tıp Fakültesi Tıp Eğitimi ve Bilișimi Anabilim Dall

Emel KAPLAN

Marmara Üniversitesi Sağllk Hizmetleri Meslek Yüksekokulu Emekli Öğretim Görevlisi

\begin{abstract}
Learning is defined as the process by which an individual actively and consciously acquires knowledge using some strategies and combines them with knowledge that exists in the memory to form lasting behaviors. The aim of this study was to determine the learning strategies and characteristics that may be related with learning strategies of Anesthesia Technician students. This study was planned as a cross sectional design. In the study 142 students were enrolled. "Learning Strategies Inventory" was used in this study. SPSS 17.0 statistical programme was used for data analysis. The data was evaluated by frequency, one way ANOVA and t test. The mean score of attention strategies of students of Anesthesia Department was $15.26 \pm 2.33$; the mean score of rehearsal strategies was $16,10 \pm 2,46$; The mean score of elaboration strategies was $24.41 \pm 4.95$; the mean score of memory placement strategies was $6,69 \pm 1,59$; the mean score of recall strategies was $13,64 \pm 2,93$; the mean score of cognitive management strategies was $17,26+3,66$; the mean score of affective strategies was 20,45 $\pm 3,71$. As a result of this study, it is determined that elaboration strategies, rehearsal strategies and affective strategies are the most used by Anesthesia technician students. A statistically significant difference was found between 1st class 1 st education and 2 nd class 2 nd education in terms of mean score of rehearsal strategies $(p<0.05)$. In conclusion, it is suggested that students have to determine and develope their learning strategies.
\end{abstract}

Keywords: Anesthesia Technician, Learning, Learning Strategy

\section{GíRiş}

Öğrenme, bireyin aktif ve bilinçli olarak bazı stratejileri kullanarak çevreden bilgi edinme, hafizada var olan bilgilerle birleştirerek kalıcı davranışlar oluşturma süreci olarak tanımlanmaktadır. Bu süreçte birey kısa ve uzun süreli hafızasında bulunan bilgileri çeşitli yöntem ve uygulamalarla yeniden düzenlemek zorundadır (1). Öğrenmenin özellikleri ise; davranışta gözlenebilir bir 
değişme olması, davranıştaki değişmenin nispeten sürekli olması, davranıştaki değişmenin yaşantı kazanma sonucunda olması, davranıştaki değişmenin geçici bir biçimde meydana gelmemesi ve davranıştaki değişmenin sadece büyüme sonucunda oluşmaması olarak gösterilmektedir $(2,3)$.

Yunanca "stratos" ordu ve "ago" gütmek kelimelerinden gelen "strateji" kavramı, önceden belirlenen bir amaca ulaşmak için belirlenen yol anlamına gelmektedir (4). Bir başka ifade ile "strateji" kavramı, hangi yöntem, teknik ve taktiklerin işe koşulacağının belirleyicisidir. (5).

Öğrenme stratejisi kavramı ise, Özer'in belirttiğine göre "bireyin kendi kendine öğrenmesini kolaylaştıran tekniklerin her biridir" (6). Öğrenme stratejileri bir düşünce ya da davranış örüntüsü ya da zihinsel işlemleri içeren özel teknikler olarak ele alınırken, bazı araştırmacılar bu kavramı bir tür plan olarak değerlendirmektedir (7). Ellez öğrenme stratejilerini şöyle tanımlamıştır; "Öğrenme stratejileri öğrenme sırasında kullandığımız bilişsel süreçlerle ilgili bilerek ya da bilmeyerek yaptığımız öğrenmelerimizi etkileme amacında olan davranışlardır” (8). İlköğretim ve ortaöğretim öğrencileri üzerinde yapılan çalışmalarda, öğrenme stratejilerinin, öğrenciyi bilinçli öğrenci durumuna getirdiği, öğrencinin öğrenmedeki verimliliğ̣ini arttırdığı, öğrenciye bağımsız öğrenebilme yeteneği kazandırdığı, ögrencinin isteyerek ve zevk alarak öğrenmesine yardım ettiği ve öğrencinin okul sonrası öğrenmelerine temel hazırladığı belirtilmiştir (9).

Hızla değişen dünyada, bilginin ve bilgi tabanının sürekli ve artarak değişmesi ve bireyin öğrenme beklentilerinin artması, eğitim uygulamaları sırasında öğrenme-öğretme sürecinin verimliliğginin arttırılmasını gerekli kılmaktadır (10). Öğrenme ve öğretme sürecinin verimliliğinin arttırılması için öğrencilerin okulda ve okul sonrası yaşamlarında gerekli olan öğrenmelerde başarılı olabilmelerinin ön koşulu "etkili öğrenme" yollarını bilmektir. Etkili öğrenme yolları araştırıldığında, bireyin öğrenmeyi öğrenmesi gerektiği kavramı ortaya çıkmaktadır. Ayrıca bu kavram, öğrencinin kendi başına öğrenmesini kolaylaştıran teknikler olarak bilinen öğrenme stratejilerini kapsadığı da görülmektedir. Öğrenme stratejileriyle öğrenci kendi öğrenmesinden sorumlu hale gelmekte, en iyi ne şekilde öğrendiğinin farkına varmaktadır. $\mathrm{Bu}$ nedenle tüm öğretim kademelerindeki öğrencilerin öğrenme stratejilerini öğrenmelerine gereksinim duyulmaktadır (11). Öğrencinin kullanacağ kendi öğrenmelerini yönlendirebilmesine, sürekli mesleki gelişimlerini sağlayabilmesine yardımcı olabilecek ve sonuçta toplumsal verimliliğin artmasında önemli bir role sahip olabilecektir (12). Bu stratejiler bireyin yaşam boyu karşılaşabileceği diğer problemleri çözmelerinde de yardımc1 olabilecektir (13).

Genel öğrenme stratejilerinin üniversite öğrencileri tarafından kullanılma durumlarının araştırıldığı bir çalışmada, öğrencilerin en fazla bilişi yönetme stratejisini ve en az da tekrar stratejisini kullandıkları tespit edilmiştir (14). Uludağ Üniversitesi Eğitim Fakültesinde yürütülmüş olan bir araştırmada da öğrencilerin öğrenme stratejilerini sıklıkla kullandıkları saptanmıştır (15).

Öğrenme sürecinin etkili olabilmesi için öğrenme stratejilerinin farkında olmak, nerede hata yaptığını bilmek ve öğrenmenin kalıcılığını sağlamak her öğrenen de olduğu gibi Anestezi öğrencilerinde de önemlidir. Anestezi eğitimi alan öğrencilerin öğrenme stratejilerinin belirlenmesi ve bunlarla ilişkili olabilecek özellikleri incelemek amacıyla kesitsel tipte tanımlayıcı bir çalışma olarak planlanmış olan bu araştırmada yedi alt boyutta tanımlanan strateji gruplaması temel alınmıştır. Bunlar; dikkat, tekrar, anlamlandırma, zihne yerleştirme, hatırlama, bilişi yönetme ve duyuşsal stratejileridir (14).

\section{YÖNTEM}

Araştırma evrenini, Marmara Üniversitesi Sağlık Hizmetleri Meslek Yüksekokulu (SHMYO) Anestezi Bölümü 20102011 eğitim öğretim y1lı birinci ve ikinci öğretim, 1. ve 2. Sınıflarında öğrenim görmekte olan 146 öğrenci oluşturmaktadır. Araştırmada herhangi bir örnekleme yöntemi kullanılmamış olup, evrenin tamamına ulaşılmaya çalışılmıştır. Evreni oluşturan 146 öğrenciden araştırmayı kabul eden 142 öğrenciye ulaşılmıştır. Çalışmamızda, veri toplama aracı olarak kullanılan anket formu, iki ana bölümden oluşmuştur. İlk bölümde demografik bilgilerle ilgili toplam 12 soru, ikinci bölümde öğrencilere Yüksel ve Koşar'ın (2001) geliştirdiği Likert tipi bir “Öğrenme Stratejileri Ölçeği” (15) gerekli izin alınarak uygulanmıştır.

Ölçek toplam 7 alt boyuttan ve 32 maddeden oluşmaktadır. Alt boyutlar, dikkat, tekrar, anlamlandırma, zihne yerleştirme, hatırlama, bilişi yönetme ve duyuşsal stratejilerdir. Ölçekte strateji kullanım sıklığı, hiçbir zaman $=1$ puan, nadiren $=2$ puan, bazen $=3$ puan, skklıkla $=4$ puan ve her zaman $=5$ puan olarak derecelendirilmiştir. Araştırmamızda ölçeğin Cronbach's Alfa değeri 0,81 olarak saptanmıştır. 
Uygulama aşamasında, öğrencilere araştırma hakkında açılama yapıldıktan sonra sözlü onamları alınmıştır. Anketler araştırmacı tarafından öğrencilere dağıtılmış ve doldurduktan sonra geri toplanmıştır.

Verilerin değerlendirilmesinde SPSS 17.0 istatistik programı kullanılmıştır. Veriler sıklık dağılımları, tek yönlü varyans analizi (ANOVA), t-testi ile değerlendirilmiştir. Sonuçların anlamlı olup olmadığını belirlemede 0.05 anlamlılık düzeyi esas alınmıştır.

\section{BULGULAR}

Tablo 1'de görülen demografik bilgilere göre, Anestezi Bölümü öğrencilerinin \%88'i kadın, \% 12'si erkek olup, \%97,9'unun bekar, \% 2,1'i evlidir. Ankete katılan öğrencilerin \%28,9'unun 1 .sinıf $1.0 ̈ g ̆ r e t i m, \% 28,2$ 'sinin 1.sınıf 2.öğretim, \%26,1'inin 2.sınıf 1.öğretim, \%16,9'unun 2.sınıf 2.öğretim öğrencisi olduğu, \%90,8'inin sağlik meslek lisesi mezunu, \% 6,3 lise mezunu, \% 2,8 anadolu lisesi mezunu olduğu saptandı.

Tablo 1: Anestezi Bölümü Öğrencilerinin sosyo-demografik özelliklerine göre sıklıkları

\begin{tabular}{|c|c|c|c|}
\hline DEĞİŞKENLER & Kategoriler & n & $\%$ \\
\hline \multirow{2}{*}{ Cinsiyet } & Kadın & 125 & 88,0 \\
\hline & Erkek & 17 & 12,0 \\
\hline \multirow{2}{*}{ Medeni Durum } & Bekar & 139 & 97,9 \\
\hline & Evli & 3 & 2,1 \\
\hline \multirow{4}{*}{ Sinif } & 1.sınıf 1.öğretim & 41 & 28,9 \\
\hline & 1.sinıf 2.öğretim & 40 & 28,2 \\
\hline & 2.sınıf 1.öğretim & 37 & 26,1 \\
\hline & 2.sınıf 2.ögretim & 24 & 16,9 \\
\hline \multirow{3}{*}{ Mezun Olduğu Ortaöğretim Kurumu Türü } & Sağlik Meslek Lisesi & 129 & 90,8 \\
\hline & Lise & 9 & 6,3 \\
\hline & Anadolu Lisesi & 4 & 2,8 \\
\hline \multirow{8}{*}{$\begin{array}{l}\text { Üniversite Öğrenimi Sırasında İkamet } \\
\text { Durumu }\end{array}$} & Kredi Yurtlar Kurumu & 3 & 2,1 \\
\hline & Özel Yurt & 3 & 2,1 \\
\hline & Sinıf arkadaşları ile aynı evde & 1 &, 7 \\
\hline & Aile ile birlikte & 123 & 86,6 \\
\hline & Yalnız yașama & 2 & 1,4 \\
\hline & Farklı bölümlerden arkadașlarla aynı evi paylașma & 5 & 3,5 \\
\hline & Akrabanın Yanında & 4 & 2,8 \\
\hline & Lojman & 1 & .7 \\
\hline \multirow{4}{*}{ Anestezi Bölümünü Tercih Sebebi } & Mezun olduğumda iș bulma kolaylığ & 53 & 37,3 \\
\hline & Mesleği kendime yakın hissetmem & 55 & 38,7 \\
\hline & Ailemin isteği & 19 & 13,4 \\
\hline & Puanım tuttuğu için & 15 & 10,6 \\
\hline \multirow{3}{*}{ Yararlandığı Sosyal Güvenlik Kurumu } & Sosyal güvenlik kurumu & 124 & 87,3 \\
\hline & Özel sigorta & 2 & 1,4 \\
\hline & Yok & 16 & 11,3 \\
\hline \multirow{5}{*}{$\begin{array}{l}\text { Öğrenim Döneminde Maddi İhtiyaçları } \\
\text { Karşılama Durumu }\end{array}$} & Ailenin gönderdiği harçlıkla & 57 & 40,1 \\
\hline & Öğrenim Kredisi ile & 8 & 5,6 \\
\hline & Kısmi zamanlı bir iște çalıșarak & 9 & 6,3 \\
\hline & Düzenli aylık aldığ 1 iși ile & 48 & 33,8 \\
\hline & Diğger & 20 & 14,1 \\
\hline \multirow{3}{*}{ Kardeş Sayısı } & $1-3$ & 102 & 71,8 \\
\hline & $4-6$ & 36 & 25,3 \\
\hline & $>6$ & 4 & 2,8 \\
\hline \multirow{5}{*}{ Annenin Eğitim Durumu } & Okuryazar değil & 9 & 6,3 \\
\hline & Okuryazar & 10 & 7,0 \\
\hline & İlkögretim & 93 & 65,5 \\
\hline & Lise & 28 & 19,7 \\
\hline & Üniversite & 2 & 1,4 \\
\hline \multirow{5}{*}{ Babanın Eğitim Durumu } & Okuryazar değil & 4 & 2,8 \\
\hline & Okuryazar & 4 & 2,8 \\
\hline & İlköğretim & 68 & 47,9 \\
\hline & Lise & 50 & 35,2 \\
\hline & Üniversite & 16 & 11,3 \\
\hline \multirow{3}{*}{ Aile Yapısı } & Anne baba birlikte & 130 & 91,5 \\
\hline & Anne baba avr1 & 6 & 4,2 \\
\hline & Cevapsiz & 6 & 4,2 \\
\hline
\end{tabular}


Tablo2'degörüldüğügibiAnesteziBölümüöğrencilerinin genel öğrenme stratejileri alt boyutlarının puan ortalamaları; dikkat stratejileri 15,26 $\pm 2,33$; tekrar stratejileri $16,10 \pm 2,46$; anlamlandırma stratejileri $24,41 \pm 4,95$; belleğe yerleştirme stratejileri $6,69 \pm 1,59$; hatırlama stratejileri $13,64 \pm 2,93$; bilişi yönetme stratejileri $17,26 \pm 3,66$; duyuşsal stratejiler $20,45 \pm 3,71$ olarak saptand 1 .

Anestezi Bölümü öğrencilerinin genel öğrenme stratejileri alt boyutlarının puan ortalamaları öğrencilerin bulunduğu sınıfa göre karşılaştırıldığında Tablo 3 'teki veriler elde edildi. Buna göre, tekrar stratejileri puan ortalamas1 yönünden 1.sınıf 1.öğretim ve 2.sınıf 2.öğretim arasında istatistiksel olarak anlamlı farklılık saptand $1(\mathrm{p}<0.05)$.
Birinci sınıf 1.öğretim öğrencilerinin tekrar stratejileri puan ortalamasının 2.sınıf 2.öğretim öğrencilerinin tekrar stratejileri puan ortalamasına göre daha yüksek olduğu tespit edildi (Tablo 3).

Araştırma grubundaki Anestezi Bölümü öğrencilerinin cinsiyet, medeni durum, yaş, mezun olduğu ortaöğretim kurumu, üniversite öğrenimi sırasında ikamet ettiği yer, Anestezi Bölümünü tercih sebebi, yararlandığı sosyal güvenlik kurumu, öğrenim döneminde maddi ihtiyaçları karşılama durumu, annenin/babanın eğitim durumu, aile yapısı bağımsız değişkenlerine göre genel öğrenme stratejileri alt boyutları puan ortalamaları karşılaştırıldığında istatistiksel olarak anlamlı farklılık saptanmadı $(\mathrm{p}>0.05)$.

Tablo 2: Anestezi Bölümü Öğrencilerinin Genel Öğrenme Stratejileri Alt Boyutlarının Puan Ortalamaları:

\begin{tabular}{|l|c|c|c|c|}
\hline Öğrenme Stratejileri & Ortalama & SS & Minimum Değer & Maksimum Değer \\
\hline Dikkat Stratejileri & 15,26 & 2,33 & 8,00 & 20,00 \\
\hline Tekrar Stratejileri & 16,10 & 2,46 & 10,00 & 20,00 \\
\hline Anlamlandırma Stratejileri & 24,41 & 4,95 & 9,00 & 35,00 \\
\hline Belleğe Yerleştirme Stratejileri & 6,69 & 1,59 & 2,00 & 10,00 \\
\hline Hatırlama Stratejileri & 13,64 & 2,93 & 7,00 & 20,00 \\
\hline Bilişi Yönetme Stratejileri & 17,26 & 3,66 & 5,00 & 25,00 \\
\hline Duyuşsal Stratejiler & 20,45 & 3,71 & 11,00 & 30,00 \\
\hline
\end{tabular}

Tablo 3: Anestezi Bölümü Öğrencilerinin Sınıflarına Göre Genel Öğrenme Stratejileri Alt Boyutlarının Puan Ortalamalarının Karşılaştırılması:

\begin{tabular}{|c|c|c|c|c|c|}
\hline Karşılaştırılan Öğrenme Stratejileri Kategorisi & \multicolumn{2}{|c|}{ Sinıf } & Ortalamalar Farkı & $\mathbf{p}$ & $\mathbf{F}$ \\
\hline \multirow{3}{*}{ Tekrar Stratejileri } & \multirow{3}{*}{ 1.sinıf 1.öğretim } & 1.sinif 2.öğretim & 1,02744 & 0,227 & \multirow{3}{*}{2,816} \\
\hline & & 2.sınıf 1.öğretim & 0,82136 & 0,441 & \\
\hline & & 2.sınıf 2.öğretim & 1,73577 & $0,030 *$ & \\
\hline
\end{tabular}

*İstatistiksel anlamlılık

\section{TARTIŞMA}

Çalışmamız neticesinde Anestezi Bölümü öğrencilerinin en fazla "anlamlandirma", “tekrar" ve "duyuşsal”" stratejileri kullanmakta oldukları tespit edildi. Anlamlandırma stratejileri, bilgiler arasında ilişki kurarak anlamlı öğrenmeyi sağlayan stratejilerdir. Öğrenciler, bu stratejilerle, öğrenmeyi amaçladıkları yeni bilgiyi, daha önce öğrendikleri ve uzun süre belleklerinde var olan bilgilerle bütünleştirerek, ona anlam yükleyerek öğrenirler (16). Tekrar stratejileri ise konuyu sesli olarak ve önemli kısımları zihinde tekrarlama, yazılı metnin tümünü veya önemli cümlelerini aynen yazma ve not alma, önemli kısımların altını çizme ve metni aynen ezberleme 
gibi taktikleri içeren, ders çalışmak için daha fazla zaman gerektiren aktiviteleri içerir. Duyuşsal stratejiler ise öğrencinin öğrenme sırasında dikkatini toplaması ve sürdürmesi, konsantre olması, kaygıyı azaltması, zamanını etkili kullanması, motivasyonunu sağlaması ve sürdürmesi için kullandığı stratejilerdir (17). Anestezi Bölümü öğrencilerinin en fazla anlamlandırma, tekrar ve duyuşsal stratejileri kullanmakta oldukları bulgusunu destekleyecek şekilde okul öncesi öğretmen adaylarının öğrenme stratejilerinin belirlenmesine yönelik yapılan bir araştırmada da öğrencilerin en fazla "tekrar" ve "duyuşsal" stratejileri kullandıkları tespit edilmiştir (13). Ambulans ve Acil Bakım Teknikerliği eğitimi alan öğrencilerin öğrenme stil ve stratejilerinin incelenmesine yönelik yapılan bir araştırmada da en fazla duyuşsal ve tekrar stratejilerini kullandıkları tespit edilmiştir (17).

Beden Eğitimi ve Spor Yüksekokulu öğrencilerinin öğrenme stratejilerinin belirlenmesine yönelik yapılan bir araştırmada öğrencilerin öğrenme stratejilerini kullanma düzeylerinin yaş değişkenlerine göre farklılaşıp farklılaşmadığının incelenmesinde öğrencilerin genel öğrenme stratejilerinin bütün boyutlarını kullanma düzeylerinin yaş değişkenine göre farklılaşmadığı tespit edilmiştir (16). Aynı şekilde bir başka araştırmada da sadece "Dikkat" stratejilerinde okul öncesi öğretmen adaylarının yaşlarına göre anlamlı farklılık bulunmuş olup, diğer öğrenme stratejileri açısından yaşa göre bir farklılık saptanmamıştır (13). Bizim araştırmamızın bulgularında da Anestezi Bölümü öğrencilerinin yaş gruplarına göre öğrenme stratejileri alt boyutları puan ortalamaları karşılaştırıldığında istatistiksel olarak anlamlı farklılık saptanmamıştır ( $>0.05)$. Bu durum Anestezi Bölümü öğrencilerinin yaşlarına bağlı olmaksızın ögrenme stratejilerini benzer olarak kullandıklarını düşündürmektedir.

Bu çalışma, Sağlık Hizmetleri Meslek Yüksekokulu Anestezi Bölümü öğrencileri üzerinde yürütülmüş olduğu için sonuçların genellenebilirliği sınırlıdır. Ancak mesleki eğitim veren diğer bölümlerde de uygulanabilir olduğu gösterilmiştir. Çalışmamız, mesleki eğitimde öğrenme stratejileri ve bu stratejileri etkileyen faktörlerin belirlenmesine yönelik kantitatif ve kalitatif araştırmalara önemli bir örnek oluşturmaktadır. Sonuç olarak, bireylerin kendi öğrenme stratejilerini saptamaları ve kendileri için uygun olan öğrenme stratejilerini kullanmaları ve geliştirmeleri gereklidir. İyi bir öğretim gerçekleştirmek için, öğrencilere nası öğreneceklerini öğretmek önemlidir.

\section{KAYNAKLAR}

1. Namlu A. G. Bilișötesi Öğrenme Stratejileri Ölçme Aracının Geliştirilmesi: Geçerlilik ve Güvenirlilik Çalışması. Anadolu Üniversitesi Sosyal Bilimleri Dergisi. 2004; 4 (2): 123-136.

2. Senemoğlu N. Gelişim Öğrenme ve Öğretim. Spot Matbaas1. Ankara 1997.

3. Açıkgöz K. Etkili Öğrenme ve Öğretme. Tanyılmaz Matbaası. İzmir 1996.

4. TDK Türkçe Sözlük. Türk Dil Kurumu Yayınları. Ankara 1998.

5. Snowman J. (Edit. : G.D. Phye and T. Andre) Learning Tactics and Strategies Cognitive Classroom Learning: Understanding, Teaching and Problem Solving. Academic Pres, Inc. New York 1998.

6. Özer B. Öğrenmeyi Öğretme, Öğretimde Planlama ve Değerlendirme. Anadolu Üniversitesi Yayınları, Eskişehir 2001: 161-172.

7. Babadoğan C. Modern Öğretim Stratejilerinin Öğretim Öğrenim Süreçlerine Yansıması. Ankara Üniversitesi. Ankara 1996.

8. Ellez M. Etkin Öğrenme, Strateji Kullanımı, Matematik Başarısı, Güdü ve Cinsiyet İlişkileri. Dokuz Eylül Üniversitesi Eğitim Bilimleri Enstitüsü Yayınlanmamış Doktora Tezi. İzmir 2004.

9. Özer B. İlköğretim ve Ortaöğretim Okullarının Eğitim Programlarında Öğrenme Stratejileri. Eğitim Bilimleri ve Uygulama. 2002; 1(1): 17-32.

10. Somuncuoğlu Y, Yıldırım A. Öğrenme Stratejileri: Teorik Boyutları, Araştırma Bulguları ve Uygulama İçin Ortaya Koyduğu Sonuçlar (Learning Strategies: Theory, Research and Implications for Practice). Eğitim ve Bilim. 1998; 110: 31-39.

11. Uyar M. Eğitim Fakültesi Öğrencilerinin Ders Çalışmada Öğrenme Stratejileri Kullanım Sıklığının ve Akademik Başarılarının Karşılaştırılmalı Olarak İncelenmesi. Süleyman Demirel Üniversitesi Sosyal Bilimler Enstitüsü Eğitim Bilimleri Anabilim Dalı Yayınlanmamış Yüksek Lisans Tezi. Isparta 2008.

12. Açıkgöz K. Etkili Öğrenme ve Öğretme. Kanyılmaz Matbaası. İzmir 1998.

13. Hamurcu H. Okulöncesi Öğretmen Adaylarının Kullandıkları Öğrenme Stratejileri. Hacettepe Üniversitesi Eğitim Fakültesi Dergisi. 2002; 23: 127-134.

14. Öztürk B. Genel Öğrenme Stratejilerinin Öğrenciler Tarafından Kullanılma Durumları. Gazi Üniversitesi Sosyal Bilimler Enstitüsü Yayımlanmamış Doktora Tezi. Ankara 1995.

15. Yüksel S, Koşar E. Eğitim Fakültesi Öğrencilerinin Ders Çalışırken Kullandıkları Öğrenme Stratejileri. Çağdaş Eğitim Dergisi. 2001; 278: 29-36.

16. Çağlayan H S, Şirin EF, Yıldız Ö. Beden Eğitimi Ve Spor Yüksekokulu Öğrencilerinin Genel Öğrenme Stratejilerini Kullanma Düzeylerinin TSA. 2008; 12 (2): 45-62.

17. Güllerci H. ve Oflaz F. Ambulans ve Acil Bakım Teknikerliği Eğitimi Alan Öğrencilerin Öğrenme Stil ve Stratejilerinin İncelenmesi. Gülhane Tıp Dergisi. 2010; 52: 112-120. 
